- Review -

\title{
ENU-Based Gene-Driven Mutagenesis in the Mouse: A Next-Generation Gene-Targeting System
}

\author{
Yoichi GONDO, Ryutaro FUKUMURA, Takuya MURATA, and Shigeru MAKINO
}

Mutagenesis and Genomics Team, RIKEN BioResource Center, 3-1-1 Koyadai, Tsukuba, Ibaraki 305-0074, Japan

\begin{abstract}
As a new mouse mutant resource, the RIKEN ENU-based gene-driven mutagenesis system in the mouse has been available to the research community since 2002. By using random base-substitution mutagenesis with ENU, a new reverse genetics infrastructure has been developed as a next-generation gene-targeting system. The construction of a largescale mutant mouse library and high-throughput mutation discovery systems were the keys making it practically feasible. The RIKEN mutant mouse library consists of $\sim 10,000 \mathrm{G} 1$ mice, within which 100-150 mutant strains have been established based on users' requests every year. Use of the system is very simple: users 1 ) download an application form from our web site and send to us, and 2) design the PCR primers for the target gene. Then, we screen the RIKEN mutant mouse library and report all the detected mutations to the user. From among the allelic series of discovered mutations, users decide which mutant strain(s) to analyze and request the live mutant strain for functional studies of the target gene. Users have been reporting various functional mutations in the RIKEN mutant mouse library: e.g., missense, knockout-type and even functional non-coding mutations. In the near future, next-generation re-sequencing systems should drastically enhance the utility of the ENUbased gene-driven mutagenesis not only for the mouse but also for other species.
\end{abstract}

Key words: ENU mutagenesis, functional genomics, model mouse, reverse genetics

\section{Introduction}

In 1997, large-scale ENU mouse mutagenesis projects were launched in Germany and the United Kingdom [5, 14, 15, 23]. Their major objectives were to develop a new infrastructure for mammalian functional genomics by foreseeing the completion of whole sequencing of the human genome by the Human Genome Project. ENU is known to be the most potent chemical mutagen in the mouse, inducing heritable base substitutions in spermatogonia $[24,27,28]$. By inducing point mutations genomewide, mutant mice can be used to explore biological functions of genomic DNA sequences as well as to provide human disease models. The primary strategy of large-scale ENU mouse mutagenesis is the phenotypedriven approach for identifying causative genes by forward genetics. In 1999, RIKEN initiated a large-scale ENU mouse mutagenesis project and around the year 2000 about twenty such projects were being funded worldwide [11]. Major large-scale mouse mutagenesis projects are summarized in Box 1.

Another powerful mouse mutagenesis system is gene

(Received 4 May 2010 / Accepted 4 July 2010)

Address corresponding: Y. Gondo, Mutagenesis and Genomics Team, RIKEN BioResource Center, 3-1-1 Koyadai, Tsukuba, Ibaraki 305-0074, Japan 


\section{Box 1. Major large-scale mouse mutagenesis projects}

Academia Sinica Mouse Mutagenesis Program Core Facility (MMPCF): http://mmp.sinica.edu.tw/mmp/english/

Australian Phenomics Facility: http://www.apf.edu.au/

Baylor College of Medicine Mouse Mutagenesis for Development Defects:

http://www.mouse-genome.bcm.tmc.edu/ENU/MutagenesisProj.asp

Centre for Modeling Human Disease (CMHD): http://www.cmhd.ca/s

EUCOMM: http://www.eucomm.org/

German Research Center for Environmental Health ENU mutagenesis:

http://www.helmholtz-muenchen.de/en/ieg/group-functional-genetics/enu-screen/

Jackson Laboratory Heart, Lung, and Sleep Disorders (JAX HLSD) Center: http://pga .jax .org/

Jackson Laboratory Neuroscience Mutagenesis Facility: http://nmf.jax.org/

Jackson Laboratory Reproductive Genomics: http://reproductivegenomics.jax.org/

KOMP Knockout Mouse Project: http://www.komp.org/

MRC Harwell Mutagenesis: http://www.har.mrc.ac.uk/research/mutagenesis/

Neuromice: http://www.neuromice.org/

NorCOMM: http://www.norcomm.org/

Northwestern University Neurogenomics Project: http://genomics.northwestern.edu/neuro/

Oak Ridge National Laboratory Cryopreserved Mutant Mouse Bank: http://mouse.ornl.gov/research.html

RIKEN ENU Mouse Mutagenesis (Gene-driven): http://www.brc.riken.jp/lab/mutants/genedriven.htm

RIKEN ENU Mouse Mutagenesis (Phenotype-driven): http://www.brc.riken.go.jp/lab/gsc/mouse/Mutant/search.htm

Scripps Research Institute Mutagenetix: http://mutagenetix.scripps.edu/home.cfm

Sloan-Kettering Institute Mouse Project: https://mouse.mskcc.org/

Tennessee Mouse Genome Consortium (TMGC) Neuromutagenesis Project: http://www.tnmouse.org/neuromutagenesis/

Trans-NIH Mouse Initiatives: http://www.nih.gov/science/models/mouse/

In 1997, the German Research Center for Environmental Health (formally GSF) [14, 15] and MRC Harwell [5, 23] pioneered phenotype-driven ENU mutagenesis on a large scale. Then, RIKEN and the Australian Phenomics Facility started phenotype-driven ENU mutagenesis in 1999. Many other phenotype-driven ENU mutagenesis projects followed in 2000, for instance, Baylor College of Medicine, Jackson Laboratory, TMGC in US and CMHD in Canada. Using the ENU mutagenesis, RIKEN [12, 30], MRC [26], and Oak Ridge National Laboratory [20] also started gene-driven mutagenesis in 2000. In 2006, the knockout mouse projects, KOMP, EUCOMM and NorCOMM were initiated as gene-driven mutagenesis by using conventional gene-targeting technology in ES cells $[1,2]$. No institution or center conducts just one approach exclusively; they all combine phenotype-driven and gene-driven and/or interact with other mutagenesis project(s). Only the currently active WEB sites are listed here and more details may be found on each WEB site.

targeting or the knockout (KO) mouse [7, 34]. A target gene is disrupted in the genomic DNA of embryonic stem (ES) cells with a selectable marker gene. The established ES cell line carrying the disrupted target-gene then gives rise to live mice through germline chimeras. Thus, KO mice are developed by gene-driven mutagenesis, a process that is also called reverse genetics. In 2003, the genomewide knockout mouse project was proposed [1, 2] and since 2006 three international knockout mouse projects, KOMP, EUCOMM and NorCOMM (Box 1), have been developing knockout mice.

In this review, the current status, utility, and future perspectives of the RIKEN ENU-based Gene-driven Mutagenesis System (RGDMS) for the mouse are summarized. RGDMS is another gene-driven mutagenesis system which utilizes mutations randomly induced by ENU. This paradoxical mutagenesis system became feasible with the development of the infrastructure of large-scale ENU mouse mutagenesis and the advancement of various high-throughput discovery systems of base substitutions in mammalian genomes.

\section{ENU Mouse Mutagenesis}

ENU randomly induces base substitutions in the genome; therefore, the primary goal of the ENU mouse mutagenesis project is to establish mutant mice with the phenotype-driven approach, which is nowadays called forward genetics. The basic scheme for producing mutant mice with ENU is depicted in Fig. 1. At RIKEN, 
A

G1

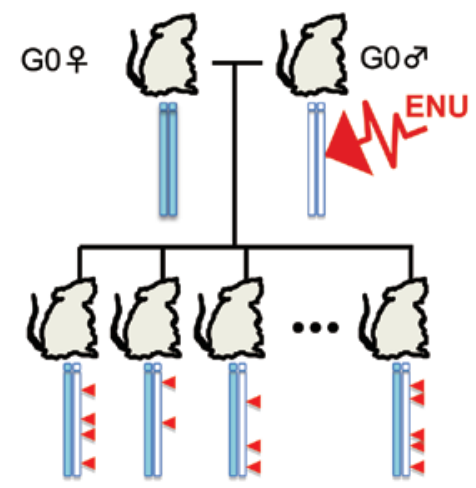

B

G2

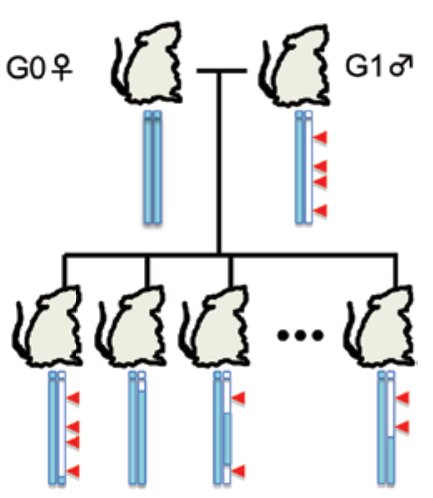

Fig. 1. Overview of large-scale ENU mouse mutagenesis. (A) Generation-0 (G0) males are treated with ENU and mated with G0 females to produce G1 mice. Germline mutations (red triangles) are induced in spermatogonia of G0 mice and inherited by G1 offspring. Each G1, therefore, carries independent ENU-induced genomewide mutations. Only one homologous chromosome pair is illustrated in this figure. In the phenotypedriven mutagenesis, G1 mice are subjected to comprehensive phenotype screens to identify candidate traits of mutations. As shown in this scheme, all the ENU-induced mutations are heterozygous in G1 mice, so all the detected mutant phenotypes are dominant. (B) G1 mice that exhibit candidate traits are then subjected to the inheritance test. When a candidate trait is caused by an ENU-induced mutation, it is inherited by $\mathrm{G} 2$ offspring with a 1:1 ratio. In this inheritance test, females from the same inbred strain used for G0 female are often mated with G1 candidate males. By using different inbred strains for G0 females and G0 males, the mating between G0 female and G1 male provides backcross $\mathrm{G} 2$ offspring. The linkage analysis of genetic markers (e.g., microsatellites and SNPs) between G0 parental strains, thereby gives rise to the mapping information of the mutant phenotype.

C57BL/6J males were treated with ENU; they were the Generation-0 (G0) parental mice. G0 males were then mated to either DBA/2J or $\mathrm{C} 3 \mathrm{H} / \mathrm{HeJ}$ to produce $\mathrm{G} 1$ mice (Fig. 1A). All the G1 mice were then subjected to comprehensive phenotyping to detect heritable traits with phenotype-driven mutagenesis. It is noteworthy that phenotype-driven ENU mouse mutagenesis was therefore originally focused on the development of dominant mutant mouse strains.

The RIKEN project particularly focused on late-onset phenotypes to find model mutant mice for common diseases, aging-related diseases and tumors in human. Once candidate G1 mice were found then they were mated to produce $\mathrm{G} 2$ offspring to propagate the mutant allele and to see if the identified phenotype was transmitted in Mendelian fashion (Fig. 1B). For late-onset phenotypes, however, the $\mathrm{G} 1$ candidate mice often became sterile or even die without producing any G2 offspring. Thus, it was crucial to preserve all the G1 strains before the onset of such potentially fatal phenotypes. We chose to keep all the G1 male strains with their frozen sperm by Nakagata's method [22]. G1 female strains, however, were not preserved, because a cryopreservation method for mouse ovaries has not yet been established which has sufficient efficiency in terms of recovery rate, cost effectiveness and labor intensiveness. It is noteworthy that the establishment of an effective ovary preservation method should significantly enhance the utility of RGDMS and next-generation gene targeting as described later in the "Future Perspectives."

\section{Mutant Mouse Library}

The basic infrastructure of RGDMS is the dual archives of frozen sperm and genomic DNA samples of Generation-1 (G1) mice produced by ENU mutagenesis (Fig. 2A). We call the dual archives the "mutant mouse library", since allelic series of multiple mutant alleles of any mouse gene are preserved as described in detail later. 


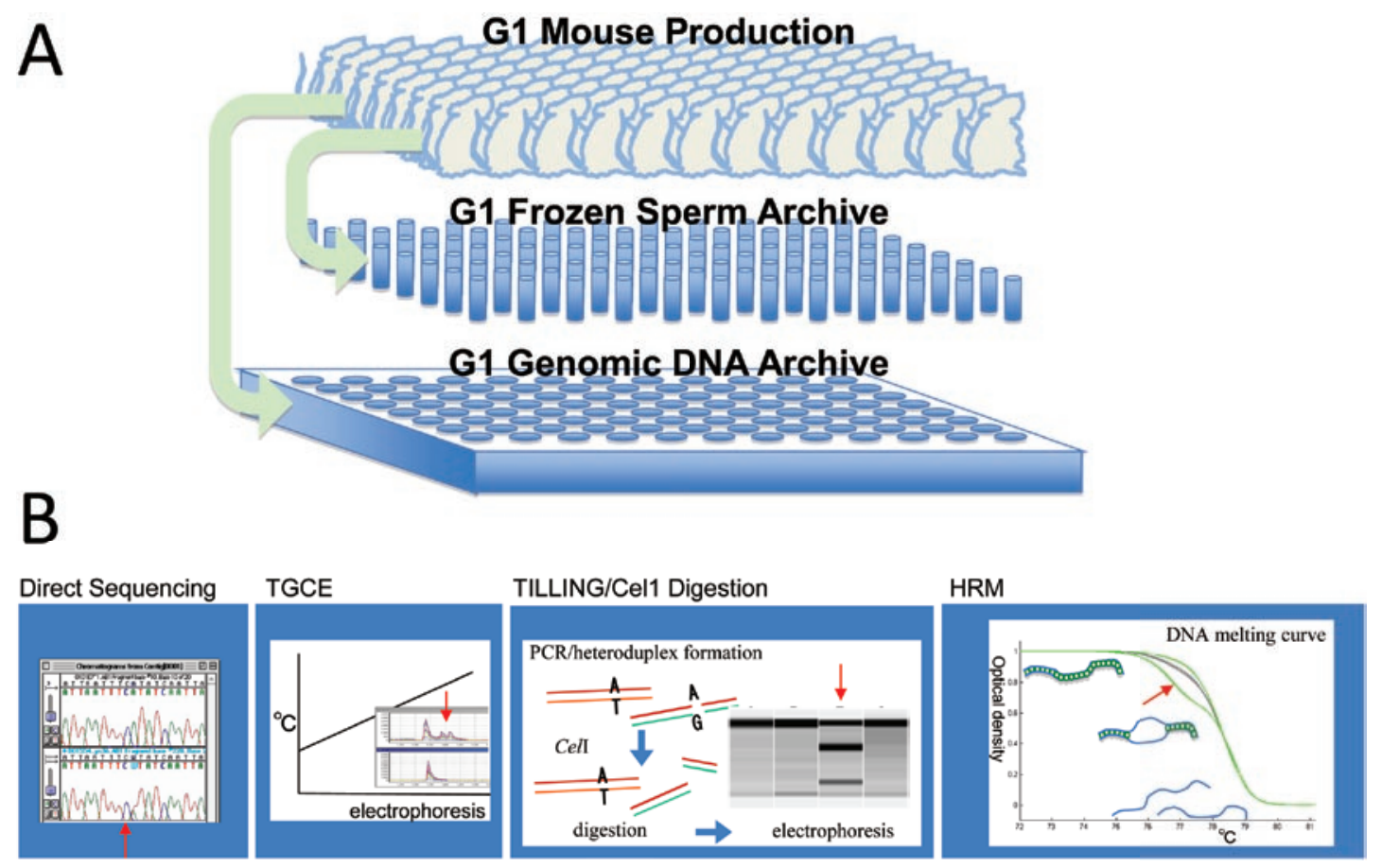

Fig. 2. Mutant mouse library and mutation discovery systems. (A) All the G1 male strains are preserved as frozen sperm. At the same time, genomic DNA samples are also extracted from all the corresponding G1 males to construct genomic DNA archive. The dual archives of the cryopreserved sperm and genomic DNA samples of the G1 mice comprise the mutant mouse library. The genomic DNA archive is subjected to a mutation screen with PCR amplification of the target gene. The G1 mouse carrying the ENU-induced mutation in the target gene is then revived from the cryopreserved sperm archive by in vitro fertilization and embryo transfer technology to produce live G2 mice. As shown in Fig. 1B, ENU-induced mutations are heterozygously inherited from G1 mice by G2 offspring with a 50\% probability. After genotyping of the identified mutation in the revived G2 offspring, the heterozygous pairs are intercrossed to produce G3 mice, in which the genotypes segregate according to Mendel's 1:2:1 ratio. This allows us to detect and analyze any recessive trait(s) of the identified mutation in the G3 homozygotes. (B) Representative mutation discovery systems are depicted. All the heteroduplex detection methods, TGCE, TILLING/Cel1 digestion and HRM, are quick and sensitive enough to identify heterozygous ENU-induced mutations in the G1 genomic DNA archive with good cost performance. The PCR samples encompassing heteroduplex DNA are then subjected to direct sequencing to identify the site and type of the base substitution in the PCR fragment.

Another critical issue in making RGDMS practically possible is how to find multiple mutations in a given target gene. We conducted a feasibility study of screening of ENU-induced mutations in G1 genomic DNAs and the ENU-induced mutation rate was primarily estimated to be 1 mutation per megabase pairs $(\mathrm{Mb})$ in $\mathrm{G} 1$ genomic DNA [13, 30, 31]. In other words, 3,000 ENUinduced mutations may be randomly induced in a given G1 mouse, since the size of the mouse genome is approximately $3 \times 10^{9} \mathrm{bp}$.

\section{High Throughput Mutation Discovery Systems}

The basic method for identifying ENU-induced mutations in a given target gene is to first amplify the genomic DNA sequence(s) of the target gene by PCR and then to screen the mutations in the large number of PCR products quickly and efficiently. As noted above, it is necessary to screen a total of $1 \mathrm{Mb}$ of G1 genomic DNA samples in order to discover one ENU-induced mutation on average. If we expect to find one mutation with $>90 \%,>95 \%$, and $>99 \%$ probabilities, we should screen a total of $>2.31 \mathrm{Mb},>3.00 \mathrm{Mb}$ and $>4.61 \mathrm{Mb}$ of G1 
genomic DNA, respectively, based on a Poisson distribution of ENU-induced mutations in the mouse genome. The random distribution of ENU-induced mutations has been experimentally confirmed [30]. It implies that if we screen $461 \mathrm{bp}$ of the target sequence after PCR amplification of 10,000 G1 mouse genomic DNA samples, we may find 4.61 ENU-induced mutations on average and may find at least one ENU-induced mutation with 99\% probability. To practically conduct such large-scale screening of ENU-induced base substitutions, it is necessary to adopt a high-throughput and cost-effective mutation discovery system.

Various point mutation discovery systems have been adopted for the ENU-based gene-driven mutagenesis system. At RIKEN, we first used the direct sequencing (DS) method using ABI3700/3730 automated 96-well Sanger sequencers (Applied Biosystems/Life Technologies, Carlsbad, CA, USA). Then, we have been comparing several heteroduplex detection methods: 1) the temperature gradient capillary electrophoresis (TGCE) method [9, 17, 21] with SCE9610 (SpectruMedix, State College, PA, USA), 2) the TILLING/Cel1 digestion method [25, 35] simplified with HAD-GT12 (eGENE/ Qiagen, Hilden, Germany), and 3) the high resolution melting (HRM) method [4, 37] with LightScanner (Idaho Technology, Salt Lake City, UT, USA) or Light Cycler 480II (Roche, Basel, Switzerland). A schematic summary is provided in Fig. 2B.

All the tested mutation discovery systems have been effective enough to discover ENU-induced mutations. By using these high throughput mutation discovery systems (Fig. 2B), we have been able to identify and establish allelic series of mutant strains for any target gene in the mouse by identifying roughly $100-150$ mutations per year. Recently, we have mainly been using the HRM method, since it does not require any electrophoresis to detect mutations. Also, HRM is often sensitive enough to distinguish between two different homozygous base substitutions and to detect the difference between one and two mutations in a given PCR product. Recently, Dr. Serikawa's group developed the MuT-POWER method, another sensitive and high-throughput heteroduplex detection system, which has been shown to be a very effective mutation discovery system for screening point mutations in the rat [18].

\section{Archived Mutations}

The G1 sperm archive, held in liquid nitrogen tanks, semi-permanently preserves ENU-induced mutations. By constructing a G1 sperm archive that is large enough to accumulate randomly induced ENU mutations, multile G1 strains would have independently induced mutations in any given gene. It depends on the number of cryopreserved G1 mice and the ENU-induced mutation rate in the G0 spermatogonia how many mutant strains per gene would exist. We have so far preserved approximately 10,000 G1 males' frozen sperm [30]. Thus, a total of $3 \times 10^{7}$ ENU-induced mutations have been archived as shown in Fig. 3. Namely, one ENU-induced mutation is expected to exist every $100 \mathrm{bp}$ on average $\left(=3 \times 10^{9} \mathrm{bp}\right.$ of the mouse genome divided by $3 \times 10^{7}$ mutations) in the G1 frozen sperm archive at RIKEN.

The best estimate of the average size of the open reading frame (ORF) of the mouse seems to be at least 1,437 bp [10] within which $\sim 14$ ENU-induced mutations on average may exist in the RIKEN frozen sperm archive of $10,000 \mathrm{G} 1$ males. It is large enough to provide allelic series of point mutations in any target gene of the mouse for gene-driven mutagenesis with randomly induced ENU mutations. The current RIKEN mutant mouse library, therefore, is considered to have a 14-fold coverage of the allelic series of ENU-induced mutations, on average, in any given target gene. The ENU-induced mutations are distributed in accordance with the Poisson distribution [30]; therefore, neither hot nor cold spots for ENU mutagenesis exist in the mouse genome. Only a slight bias of ENU mutagenesis has so far been found in non-transcribed strands, in which base substitutions were induced more often than in transcribed strands of DNA double helices [33].

\section{Utilization of RGDMS}

When we established the mutation screening system in 2002, we immediately opened RGDMS to the research community through our WEB site (http://www.brc.riken . go.jp/lab/mutants/genedriven.htm). Researchers who have expertise in analyzing mutant mice are eligible to use RGDMS. The availability of RGDMS should encourage individual researchers who originally propose 


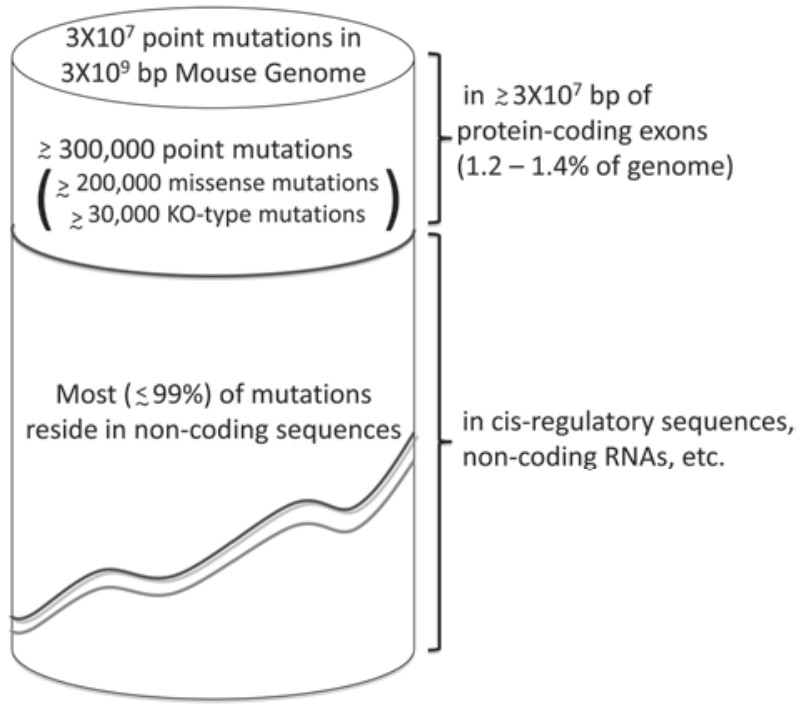

Fig. 3. Accumulated mutations in RIKEN mutant mouse library. At RIKEN, approximately 10,000 G1 males have been archived as a frozen sperm archive. Each G1 mouse carries $\sim 3,000$ ENU-induced mutations; therefore, the RIKEN mutant mouse library contains a total of $3 \times 10^{7}$ mutations randomly distributed in the $3 \times 10^{9}$ bp of the mouse genome. Based on spectrum analysis of ENU-induced mutations, we have already reported that 62,10 , and $28 \%$ are missense, knockout (KO)-type and synonymous mutations, respectively, when the mutations occur in the protein coding sequences $[12,30]$. The protein coding sequences in the human and mouse genomic DNA have been estimated to be $1.2-1.4 \%$ of the whole genomic DNA sequences. Therefore, at least $1 \%\left(=3 \times 10^{5}\right)$ of the $3 \times 10^{7}$ ENU-induced mutations are in the protein-coding sequences. This implies that there are $\sim 200,000$ and $\sim 30,000$ missense and KO-type mutations in the RIKEN mutant mouse library, respectively. In this spectrum analysis, nonsense mutations and splicing signal mutations in the splicing donor and acceptor dinucleotide sequences were regarded as KO-type mutations $[12,30]$. Primarily, missense mutations and KO-type mutations are considered to encompass functional mutations; however, mutations in non-coding sequences are occasionally known to affect phenotypes as well.

a feasible research plan for their target gene by making easy access to mutant mice. All the identified and developed mutant strains with their derivatives also must be made openly available to the research community at an appropriate time. The basic idea is to advance the fields of mutagenesis as well as mouse genetics and to accelerate studies on mammalian genome functions. Here, we describe how to access and use the RGDMS (Fig. 4).
1. A researcher (USER) first downloads the application form from our WEB site (http://www.brc.riken. go.jp/lab/mutants/genedriven.htm), and sends it to us.

Note 1: USER may apply for any target gene(s) except those that are already on our target gene list (http://www.brc.riken.go.jp/lab/mutants/genedriven_name.htm). The list contains the genes already requested by others. We, at the same time, encourage all USERs to collaborate as much as possible when another USER tries to request the same gene.

Note 2: USER must recognize that any $\mathrm{X}$-linked genes do not have ENU-induced mutations because of the mutagenesis scheme. As shown in Fig. 1A, ENU was administered to G0 males; therefore, all the $\mathrm{X}$ chromosomes carrying ENUinduced mutations were only transmitted to G1 females, not to the archived G1 males.

2. We add the newly requested target genes to the target gene list when we update our WEB site.

3. USER designs the PCR primers with the reaction conditions and sends them to us.

Note 3: Details of PCR primer design may be found on our WEB site (http://www.brc.riken.go.jp/lab/ mutants/genedriven.htm). Briefly, the appropriate size range of the PCR product for the target sequence is about $300 \mathrm{bp}$. We used to recommend USER to design a multiplex PCR following the TGCE method [30]; however, we currently conduct mutation screening with the HRM method which cannot use any multiplex PCR products.

4. After we receive USER's PCR primers and the PCR conditions, we check the reproducibility of the PCR reactions. When the reproducibility of the PCR reaction has been confirmed, the PCR pair is added to the waiting list for mutation screening.

5. Based on the order in the waiting list, we screen mutations in the G1 genomic DNA archive. Whenever we find mutations, we report all the discovered mutations to USER.

6. USER decides which mutation(s) to analyze at the live mouse level and notifies the decision to us.

7. We arrange the necessary paper work between USER and the Experimental Animal Division (EAD) at 
USER

1. Apply a target gene(s).

3. Design PCR primers and send them to RIKEN.

6. Decide which mutation(s) to analyze and send the order form and MTA to RIKEN BRC EAD.

\section{RIKEN}

2. Add User's gene(s) to the gene list.

4

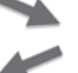

4. Add User's primers to the waiting list for screening.

5. Screen mutations and report all

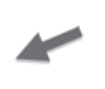
the discovered mutations to User.

\section{RIKEN BRC EAD conduct IVF/ET} to revive the requested mutant mouse.

8. Genotype the revived $\mathrm{G} 2$ progenies and send heterozygous G2 mice to User.

\section{Conduct functional studies on the target gene with mutant mice. \\ 10. Deposit useful derivative mutant mouse lines including backcrossed strains at RIKEN BRC EAD after the completion of the functional studies.}

Fig. 4. Schematic flow of RGDMS use. By simply designing PCR primer pairs for the gene of interest, researchers (USER) are able to obtain allelic series of mutant mouse strains each of which carries an independent base substitution in the target gene. The Mutagenesis and Genomics Team at RIKEN BioResource Center (BRC) is responsible for RGDMS, except the rederivation of mutant strains from frozen sperm by IVF/embryo transfer which is conducted by the Experimental Animal Division (EAD) at RIKEN BRC. EAD also distributes the established mutant mouse strains. More details are given in the text.

RIKEN BioResource Center which is in charge of the rederivation of live $\mathrm{G} 2$ mice from the specified G1 frozen sperm by in vitro fertilization and embryo transfer technology.

8. We check the genotype of the G2 mice and EAD sends USER live heterozygous mice carrying the newly identified ENU-induced mutation in the target gene.

9. USER takes the initiative to study on the mutant mice. USER has three years at most to exclusively conduct functional studies on the mutant mice.

10. When the three-years has expired, a study on the mutant mouse is published, or USER terminates the study of the mouse, whichever comes first, USER must deposit the backcrossed mutant strains and other developed derivative strains to EAD. Subsequently, all the derivative mutant strains together with the original G1 strain become available to the public through RIKEN BRC.
Note 4: As described above and depicted in Fig. 1A, the original G1 strain carries many other ENUinduced mutations. If USER discovers any such additional mutations that are unrelated to the one identified by RGDMS, USER is granted the first right to conduct studies on the additional mutations bound by the same conditions. To retain the right, USER has to report the identified mutation(s) to us at the time of discovery with the study plan.

Note 5: RGDMS is under development; thus, we do not guarantee that it can provide mutant mice to the user. Suggestions, opinions and comments are indispensable for improving RGDMS. More details, updated information and/or recent modifications to RGDMS are disclosed on our WEB site (http://www.brc.riken.go.jp/lab/mutants/jp/genedriven.htm). 


\section{Examples of Model Mice Established by RGDMS}

\section{Disrupted-in-schizophrenia 1 (Disc1) mutant strains}

Clapcote et al. [6] analyzed two independent missense mutant strains, Q31L and L100P, of the Disc1 gene. Human DISC 1 gene is a candidate gene for one of the genetic risk factors of schizophrenia. They found that the Q31L and L100P missense mutant mice provided recessive major depression and dominant schizophrenia models, respectively. Interestingly, neither the $31^{\text {st }}$ nor the $100^{\text {th }}$ amino acid residue in the mouse Disc 1 is conserved in human DISC1. The conservation of the amino acid residue is one of the clues to evaluate the functionality of the discovered ENU-induced mutations but it is not always the case as shown in the Q31L and L100P missense mutations in the Discl gene. Even if a mutation occurs in an amino acid residue that does not conserved between human and mouse, it often may have a critical function.

\section{Serine racemase (Srr) mutant strains}

Serine racemase $(S R R)$ is another candidate gene for a risk factor of schizophrenia in humans. Responding to a request to target the $\mathrm{Srr}$ gene, we found a total of 9 mutations, one of which was a nonsense mutation in Exon 9. Labrie et al. [16] analyzed the nonsense mutation and found that homozygous mice exhibited schizophrenia-like behavior. They detected a $50 \%$ reduction of Srr mRNA and no Srr proteins in homozygotes, thereby confirming that the nonsense mutation in Exon 9 of the $\mathrm{Srr}$ gene is a KO-type allele. Basu et al. [3] independently constructed a disrupted allele of the $\mathrm{Srr}$ gene using the conventional KO mouse method and reported the mostly equivalent phenotypes. Thus, RGDMS has practically provided KO-type mutations.

\section{$N$-acetyltransferase 1 (Nat1) mutant strains}

The Nat1 gene in the mouse is an intronless gene with an 870 bp of ORF. The human homolog is the NAT2 gene and NAT2 polymorphisms have been known to cause genetic variation of the susceptibility to the isoniazid (INH) treatment in tuberculosis patients. Acting on a request to target the Natl gene in the mouse, we found a total of 11 mutations in the $870 \mathrm{bp}$ of the ORF in which five missense and one nonsense mutations were identified. Erickson et al. [8] directly assayed the enzymatic activities to INH of the wild type and I95T missense mutation using the liver extracts. Compared to the wildtype control extracts, the heterozygous and homozygous extracts showed about $1 / 2$ and less than $1 / 10$ reduction of the Nat1 enzymatic activities, respectively. It directly evidences that amino acid substitutions by ENUinduced mutations do indeed alter the enzymatic activities of mutant proteins.

\section{Mammal-fish-conserved-sequence 1 (MFCS1) mutant strains}

Following a request to test the $c i s$-regulatory function of the non-coding sequence [29], we screened the MFCS1 sequence and found 6 mutant strains. Masuya et al. [19] analyzed the mutant phenotype and the expression of the regulated Sonic hedgehog $(S h h)$ gene. Among the three tested mutant strains, one mutant strain, M-1116, exhibited dominant polydactyly associated with the ectopic expression of Shh in limb bud development. Therefore, some ENU-induced mutations in non-coding sequences are functional.

\section{Current Status and Issues of RGDMS}

By using heteroduplex detection systems, we have been discovering 100-150 ENU-induced mutations in the target genes requested by many researchers every year. At present, the target gene list shown on our WEB site has 317 target genes. In the previous section, we showed RGDMS has provided various types of ENUinduced mutations: missense mutations, KO-type mutations and non-coding functional mutations. We have already shown that 62 and $10 \%$ of ENU-induced mutations in the protein coding sequences are amino acid substitutions and KO-type mutations, respectively [12, 30], and this is summarized in Fig. 3.

As described in the previous section, the nonsense mutation found in the Srr gene exhibites phenotypes that are equivalent to those of conventional $\mathrm{KO}$ mice $[3,16]$. The finding of $\mathrm{KO}$ phenotypes in ENU-based genedriven mutagenesis is common. For instance, we have found nine mutant strains by screening the $\beta$-catenin 
gene, one of which was a nonsense mutation and embryonic lethal in homozygotes. We have also found eight allelic series of ENU-induced mutations in the Smoothen gene, one of which was a mutation in the dinucleotide splicing signal and also recessive embryonic lethal. The nonsense and splicing mutations usually cause drastic change in the peptide sequences. Also, such mutations often result in the mRNA degradation due to nonsensemediated decays.

Most of the ENU-induced mutations reside in noncoding sequences (Fig. 3). Some mutations in proteincoding sequences may also be neutral or functionally silent. Even knockout mice often exhibit no phenotypic anomalies compared to control mice. One of the biggest issues in gene-driven mutagenesis is what types of mutations in genomic sequences affect the biological function. Particularly, functional studies of ENU-induced mutations in non-coding sequences are currently very challenging.

Another general issue in ENU-based gene-driven mutagenesis is the heterogeneity of the genetic background. As described above and shown in Fig. 1, ENU induces $\sim 3,000$ genomewide mutations. When we analyze the biological function of a discovered mutation in the threegeneration scheme, the mutations tightly linked to the discovered mutation are likely to co-segregate in the G3 offspring. To distinguish the effects of the discovered mutation from those of the tightly linked unidentified mutations, we usually conduct a backcross of more than 6 generations before making intercrosses to analyze the homozygous effects of the discovered mutation. The next-generation re-sequencing system should provide another tool for distinguishing the effects of the discovered mutation from others without time-consuming backcrosses.

\section{Future Perspectives}

RGDMS has been providing a number of allelic series of mutant strains of target genes to the research community. However, only a small fraction of archived ENU-induced mutations have been retrieved (Fig. 3). In order to drastically enhance the mutation discovery from the mutant mouse library, next-generation re-sequencing technologies will be the key. When a US $\$ 1,000$ re-se- quencing system becomes available, it will be practically feasible to identify all the $3 \times 10^{7}$ archived mutations in the RIKEN mutant mouse library. As shown in Fig. 3, the most of the mammalian genomes consist of repetitive and noncoding sequences. Only $1.2-1.4 \%$ are protein-coding sequences. Recently, several target enrichment systems for mammalian genomes have become available. Therefore, we have started feasibility studies of mutation screening by targeting $\sim 4 \mathrm{Mb}$ of coding exons first by using the SureSelect Target Enrichment System (Agilent, Santa Clara, CA, USA). The target enrichment was successful and the enriched samples are currently being re-sequenced using Illumina GAIIx (Illumina, San Diego, CA, USA) and SOLiD3plus (Life Technology, Carlsbad, CA, USA). In the near future, by targeting whole exons in the mouse (mouse exome) of $36-42 \mathrm{Mb}(=1.2-1.4 \%$ of the mouse genome), the RIKEN mutant mouse library should be able to provide $\sim 200,000$ missense and $\sim 30,000$ KO-type mutations to the research community.

The next-generation re-sequencing to reveal all the ENU-induced mutations in each G1 mouse should also provide a new strategy to overcome the heterogeneity issue of the G1 genetic background. Association studies between phenotypes and the target mutation as well as other ENU-induced mutations in the G1 mouse and its offspring should reveal the functional gene-to-gene interactions, often called epistatic interactions. As described in the previous section, many users of RGDMS currently conduct many backcrosses to make the discovered mutation in an identical homozygous genetic background, also called a congenic background, by eliminating other undiscovered ENU mutations. On the other hand, the next-generation re-sequencing system should reveal all the ENU-induced mutations in a given G1 strain. Therefore, it should become possible to distinguish whether the characterized phenotype(s) in the three-generation scheme is derived from one mutation or some combination of several mutations by genotyping all the segregations in the $\mathrm{G} 3$ mice and their offspring.

The ENU-based gene-driven mutagenesis system can also be applied to any species by archiving the G1 progenies. It probably is only a reverse genetic tool for most of the mammalian species, since no species other than the mouse have currently established ES cell lines. In 
fact, an ENU-based gene-driven mutagenesis system has already been started in the rat $[18,32,36]$. Another issue is the archiving of the G1 females, as described above under "ENU Mouse Mutagenesis." ENU mutagenesis has been conducted in G0 males probably because the spermatogonia keep proliferating and more susceptible to mutagens than oogonia and other female germline cells. In mice as well as rats, the G1 archive has been constructed by sperm cryopreservation, since no effective ovary cryopreservation and rederivation system has yet been established. The development of efficient ovary preservation technologies will make G1 female animals, which consist of half of the G1 offspring, available to ENU-based gene-driven mutagenesis. This will be of particular importance for $\mathrm{X}$-linked genes that are the homologs of many human X-linked diseases. Some alternative approaches to making G1 females available as a significant part of the mutant animal library are the development of clone animals from preserved female cells, and the development of an efficient mutagenesis system for female germline cells.

\section{Acknowledgments}

We express our thanks to all those who have dedicated their times to finding ENU-induced mutations in order to make mutant mouse strains available to the research community, in particular, members of the Population and Quantitative Genomics Team, RIKEN Genomic Sciences Center and the Mutagenesis and Genomics Team, RIKEN BioResource Center. This work is partly supported by KAKENHI 15200032 and KAKENHI 21240043 to Y.G., KAKENHI 20790196 to R.F. and KAKENHI 21700454 to S.M.

\section{References}

1. Austin, C.P., Battey, J.F., Bradley, A., Bucan, M., Capecchi, M., Collins, F.S., Dove, W.F., Duyk, G., Dymecki, S., Eppig, J.T., Grieder, F.B., Heintz, N., Hicks, G., Insel, T.R., Joyner, A., Koller, B.H., Lloyd, K.C., Magnuson, T., Moore, M.W., Nagy, A., Pollock, J.D., Roses, A.D., Sands, A.T., Seed, B., Skarnes, W.C., Snoddy, J., Soriano, P., Stewart, D.J., Stewart, F., Stillman, B., Varmus, H., Varticovski, L., Verma, I.M., Vogt, T.F., von Melchner, H., Witkowski, J., Woychik, R.P., Wurst, W., Yancopoulos, G.D., Young, S.G., and Zambrowicz, B. 2004. The knockout mouse project. Nat. Genet. 36:
921-924.

2. Auwerx, J., Avner, P., Baldock, R., Ballabio, A., Balling, R., Barbacid, M., Berns, A., Bradley, A., Brown, S., Carmeliet, P., Chambon, P., Cox, R., Davidson, D., Davies, K., Duboule, D., Forejt, J., Granucci, F., Hastie, N., de Angelis, M.H., Jackson, I., Kioussis, D., Kollias, G., Lathrop, M., Lendahl, U., Malumbres, M., von Melchner, H., Müller, W., Partanen, J., Ricciardi-Castagnoli, P., Rigby, P., Rosen, B., Rosenthal, N., Skarnes, B., Stewart, A.F., Thornton, J., TocchiniValentini, G., Wagner, E., Wahli, W., and Wurst, W. 2004. The European dimension for the mouse genome mutagenesis program. Nat. Genet. 36: 925-927.

3. Basu, A.C., Tsai, G.E., Ma, C.L., Ehmsen, J.T., Mustafa, A.K., Han, L., Jiang, Z.I., Benneyworth, M.A., Froimowitz, M.P., Lange, N., Snyder, S.H., Bergeron, R., and Coyle, J.T. 2009. Targeted disruption of serine racemase affects glutamatergic neurotransmission and behavior. Mol. Psychiatry 14: 719-727.

4. Bennett, C.D., Campbell, M.N., Cook, C.J., Eyre, D.J., Nay, L.M., Nielsen, D.R., Rasmussen, R.P., and Bernard, P.S. 2003. The LightTyper: high-throughput genotyping using fluorescent melting curve analysis. Biotechniques 34: 1288-1295.

5. Brown, S.D.M. and Nolan, P.M. 1998. Mouse mutagenesissystematic studies of mammalian gene function. Hum. Mol. Genet. 7: 1627-1633.

6. Clapcote, S.J., Lipina, T.V., Millar, J.K., Mackie, S., Christie, S., Ogawa, F., Lerch, J.P., Trimble, K., Uchiyama, M., Sakuraba, Y., Kaneda, H., Shiroishi, T., Houslay, M. D., Henkelman, R.M., Sled, J.G., Gondo, Y., Porteous, D.J., and Roder, J.C. 2007. Behavioral phenotypes of Disc1 missense mutations in mice. Neuron 54: 387-402.

7. Doetschman, T., Maeda, N., and Smithies, O. 1988. Targeted mutation of the Hprt gene in mouse embryonic stem cells. Proc. Natl. Acad. Sci.U.S.A. 85: 8583-8587.

8. Erickson, R.P., McQueen, C.A., Chau, B., Gokhale, V., Uchiyama, M., Toyoda, A., Ejima, F., Maho, N., Sakaki, Y., and Gondo, Y. 2008. An $N$-ethyl- $N$-nitrosourea-induced mutation in $N$-acetyltransferase 1 in mice. Biochem. Biophys. Res. Commun. 370: 285-288.

9. Gao, Q. and Yeung, E.S. 2000. High-throughput detection of unknown mutations by using multiplexed capillary electrophoresis with poly(vinylpyrrolidone) solution, Anal. Chem. 72: 2499-2506.

10. Gerhard, D.S., Wagner, L., Feingold, E.A., Shenmen, C.M., Grouse, L.H., Schuler, G., Klein, S.L., Old, S., Rasooly, R., Good, P., Guyer, M., Peck, A.M., Derge, J.G., Lipman, D., Collins, F.S., Jang, W., Sherry, S., Feolo, M., Misquitta, L., Lee, E., Rotmistrovsky, K., Greenhut, S.F., Schaefer, C.F., Buetow, K., Bonner, T.I., Haussler, D., Kent, J., Kiekhaus, M., Furey, T., Brent, M., Prange, C., Schreiber, K., Shapiro, N., Bhat, N.K., Hopkins, R.F., Hsie, F., Driscoll, T., Soares, M.B., Casavant, T.L., Scheetz, T.E., Brown-stein, M.J., Usdin, T.B., Toshiyuki, S., Carninci, P., Piao, Y., Dudekula, D.B., Ko, M.S., Kawakami, K., Suzuki, Y., Sugano, S., Gruber, C.E., Smith, M.R., Simmons, B., Moore, T., Waterman, R., Johnson, S.L., Ruan, Y., Wei, C.L., Mathavan, S., Gunaratne, P.H., Wu, J., Garcia, A.M., Hulyk, S.W., Fuh, 
E., Yuan, Y., Sneed, A., Kowis, C., Hodgson, A., Muzny, D.M., McPherson, J., Gibbs, R.A., Fahey, J., Helton, E., Ketteman, M., Madan, A., Rodrigues, S., Sanchez, A., Whiting, M., Madari, A., Young, A.C., Wetherby, K.D., Granite, S.J., Kwong, P.N., Brinkley, C.P., Pearson, R.L., Bouffard, G.G., Blakesly, R.W., Green, E.D., Dickson, M.C., Rodriguez, A.C., Grimwood, J., Schmutz, J., Myers, R.M., Butterfield, Y.S., Griffith, M., Griffith, O.L., Krzywinski, M.I., Liao, N., Morin, R., Palmquist, D., Petrescu, A.S., Skalska, U., Smailus, D.E., Stott, J.M., Schnerch, A., Schein, J.E., Jones, S.J., Holt, R.A., Baross, A., Marra, M.A., Clifton, S., Makowski, K.A., Bosak, S., and Malek, J., MGC Project Team. 2004. The status, quality, and expansion of the NIH full-length cDNA project: the mammalian gene collection (MGC). Genome Res. 14: 2121-2127.

11. Gondo, Y. 2008. Trends in large-scale mouse mutagenesis: from genetics to functional genomics. Nat. Rev. Genet. 9: 803-810

12. Gondo, Y. and Fukumura, R. 2009. ENU-induced mutant mice for a next-generation gene-targeting system. Prog. Brain Res. 179: 29-34.

13. Gondo, Y., Fukumura, R., Murata, T., and Makino, S. 2009. Next-generation gene targeting in the mouse for functional genomics. BMB Rep. 42: 315-323.

14. Hrabé de Angelis, M., and Balling, R. 1998. Large scale ENU screens in the mouse: genetics meets genomics. Mutat. Res. 400: 25-32.

15. Hrabé de Angelis, M.H., Flaswinkel, H., Fuchs, H., Rathkolb, B., Soewarto, D., Marschall, S., Heffner, S., Pargent, W., Wuensch, K., Jung, M., Reis, A., Richter, T., Alessandrini, F., Jakob, T., Fuchs, E., Kolbm, H., Kremmer, E., Schaeble, K., Rollinski, B., Roscher, A., Peters, C., Meitinger, T., Strom, T., Steckler, T., Holsboer, F., Klopstock, T., Gekeler, F., Schindewolf, C., Jung, T., Avraham, K., Behrendt, H., Ring, J., Zimmer, A., Schughart, K., Pfeffer, K., Wolf, E., and Balling, R. 2000. Genome-wide, large scale production of mutant mice by ENU mutagenesis. Nat. Genet. 25: 444-447.

16. Labrie, V., Fukumura, R., Rastogi, A., Fick, L.J., Wang, W., Boutros, P.C., Kennedy, J.L., Semeralul, M.O., Lee, F.H., Baker, G.B., Belsham, D.D., Barger, S.W., Gondo, Y., Wong, A.H., and Roder, J.C. 2009. Serine racemase is associated with schizophrenia susceptibility in humans and in a mouse model. Hum. Mol. Genet. 18: 3227-3243.

17. Li, Q., Liu,Z., Monroe, H., and Culiat, C.T. 2002. Integrated platform for detection of DNA sequence variants using capillary array electrophoresis. Electrophoresis 23: 14991511.

18. Mashimo, T., Yanagihara, K., Tokuda, S., Voigt, B., Takizawa, A., Nakajima, R., Kato, M., Hirabayashi, M., Kuramoto, T., and Serikawa, T. 2008. An ENU-induced mutant archive for gene targeting in rat. Nat. Genet. 40: 514-515.

19. Masuya, H., Sezutsu, H., Sakuraba, Y., Sagai, T., Hosoya, M., Kaneda, H., Miura, I., Kobayashi, K., Sumiyama, K., Shimizu, A., Nagano, J., Yokoyama, H., Kaneko, S., Sakurai, N., Okagaki, Y., Noda, T., Wakana, S., Gondo, Y., and Shiroishi, T. 2007. A series of ENU-induced single-base substitutions in a long-range cis-element altering Sonic hedgehog expression in the developing mouse limb bud. Genomics 89: 207-214.

20. Michaud, E.J., Culiat, C.T., Klebig, M.L., Barker, P.E., Cain, K.T., Carpenter, D.J., Easter, L.L., Foster, C.M., Gardner, A.W., Guo, Z.Y., Houser, K.J., Hughes, L.A., Kerley, M.K., Liu, Z., Olszewski, R.E., Pinn, I., Shaw, G.D., Shinpock, S.G., Wymore, A.M., Rinchik, E.M., and Johnson, D.K. 2005. Efficient gene-driven germ-line point mutagenesis of C57BL/6J mice. BMC Genomics 6: 164.

21. Murphy, K., Hafez, M., Philips, J., Yarnell, K., Gutshall, K., and Berg, K. 2003. Evaluation of temperature gradient capillary electrophoresis for detection of the factor $\mathrm{v}$ leiden mutation: coincident identification of a novel polymorphism in factor v. Mol. Diagn. 7: 35-40.

22. Nakagata, N. 2000. Cryopreservation of mouse spermatozoa. Mamm. Genome 11: 572-576.

23. Nolan, P.M., Peters, J., Strivens, M., Rogers, D., Hagan, J., Spurr, N., Gray, I.C., Vizor, L., Brooker, D., Whitehill, E., Washbourne, R., Hough, T., Greenaway, S., Hewitt, M., Liu, X., McCormack, S., Pickford, K., Selley, R., Wells, C., Tymowska-Lalanne, Z., Roby, P., Glenister, P., Thornton, C., Thaung, C., Stevenson, J.A., Arkell, R., Mburu, P., Hardisty, R., Kiernan, A., Erven, A., Steel, K.P., Voegeling, S., Guenet, J.L., Nickols, C., Sadri, R., Nasse, M., Isaacs, A., Davies, K., Browne, M., Fisher, E.M., Martin, J., Rastan, S., Brown, S.D., and Hunter, J. 2000. A systematic, genomewide, phenotype-driven mutagenesis programme for gene function studies in the mouse. Nat. Genet. 25: 440-443.

24. Noveroske, J.K., Weber, J.S., and Justice, M.J. 2000. The mutagenic action of N-ethyl-N-nitrosourea in the mouse. Mamm. Genome 11: 478-483.

25. Oleykowski, C.A., Bronson Mullins, C.R., Godwin, A.K., and Yeung, A.T. 1998. Mutation detection using a novel plant endonuclease. Nucleic Acids Res. 26: 4597-4602.

26. Quwailid, M.M., Hugill, A., Dear, N., Vizor, L., Wells, S., Horner, E., Fuller, S., Weedon, J., McMath, H., Woodman, P., Edwards, D., Campbell, D., Rodger, S., Carey, J., Roberts, A., Glenister, P., Lalanne, Z., Parkinson, N., Coghill, E.L., McKeone, R., Cox, S., Willan, J., Greenfield, A., Keays, D., Brady, S., Spurr, N., Gray, I., Hunter, J., Brown, S.D., and Cox, R. D. 2004. A gene-driven ENU-based approach to generating an allelic series in any gene, Mamm. Genome 15: 585-591.

27. Russell, W.L., Kelly, E.M., Hunsicker, P.R., Bangham, J.W., Maddux, S.C., and Phipps, E.L. 1979. Specific-locus test shows ethylnitrosourea to be the most potent mutagen in the mouse. Proc. Natl. Acad. Sci. U.S.A. 76: 5818-5819.

28. Russell, W.L., Hunsicker, P.R., Raymer, G.D., Steele, M.H., Stelzner, K.F., and Thompson, H.M. 1982. Dose-response curve for ethylnitrosourea-induced specific-locus mutations in mouse spermatogonia. Proc. Natl. Acad. Sci. U.S.A. 79: 3589-3591.

29. Sagai, T., Masuya, H., Tamura, M., Shimizu, K., Yada, Y., Wakana, S., Gondo, Y., Noda, T., and Shiroishi, T. 2004. Phylogenetic conservation of a limb-specific, cis-acting regulator for Sonic hedgehog (Shh). Mamm. Genome 15: 23-34.

30. Sakuraba, Y., Sezutsu, H., Takahasi, K.R., Tsuchihashi, K., 
Ichikawa, R., Fujimoto, N., Kaneko, S., Nakai, Y., Uchiyama, M., Goda, N., Motoi, R., Ikeda, A., Karashima, Y., Inoue, M., Kaneda, H., Masuya, H., Minowa, O., Noguchi, H., Toyoda, A., Sakaki, Y., Wakana, S., Noda, T., Shiroishi, T., and Gondo, Y. 2005. Molecular characterization of ENU mouse mutagenesis and archives. Biochem. Biophys. Res. Commun. 336: 609-616.

31. Sakuraba, Y., Kimura, T., Masuya, H., Noguchi, H., Sezutsu, H., Takahasi, K.R., Toyoda, A., Fukumura, R., Murata, T., Sakaki, Y., Yamamura, M., Wakana, S., Noda, T., Shiroishi, T., and Gondo, Y. 2008. Identification and characterization of new long conserved noncoding sequences in vertebrates. Mamm. Genome 19: 703-712.

32. Smits, B.M., Mudde, J.B., van de Belt, J., Verheul, M., Olivier, J., Homberg, J., Guryev, V., Cools, A.R., Ellenbroek, B.A., Plasterk, R.H., and Cuppen, E. 2006. Generation of gene knockouts and mutant models in the laboratory rat by ENU-driven target-selected mutagenesis. Pharmacogenet. Genomics 16: 159-169

33. Takahasi, K.R., Sakuraba, Y., and Gondo, Y. 2007. Mutational pattern and frequency of induced nucleotide changes in mouse ENU mutagenesis. BMC Molec. Biol. 8: 52.

34. Thomas, K.R., Folger, K.R., and Capecchi, M.R. 1986. High frequency targeting of genes to specific sites in the mammalian genome. Cell 44: 419-428.

35. Till, B.J., Reynolds, S.H., Greene, E.A., Codomo, C.A., Enns, L.C., Johnson, J.E., Burtner, C., Odden, A.R., Young, K., Taylor, N.E., Henikoff, J.G., Comai, L., and Henikoff, S. 2003. Large-scale discovery of induced point mutations with high-throughput TILLING. Genome Res. 13: 524530 .

36. van Boxtel, R., Toonen, P.W., Verheul, M., van Roekel, H.S., Nijman, I.J., Guryev, V., and Cuppen, E. 2008. Improved generation of rat gene knockouts by target-selected mutagenesis in mismatch repair-deficient animals. BMC Genomics 9: 460.

37. Wittwer, C.T., Reed, G.H., Gundry, C.N., Vandersteen, J.G., and Pryor, R.J. 2003. High-resolution genotyping by amplicon melting analysis using LCGreen. Clin. Chem. 49: 853-860. 